Sādhanā Vol. 37, Part 1, February 2012, pp. 59-78. (C) Indian Academy of Sciences

\title{
Electromagnetic and neutron emissions from brittle rocks failure: Experimental evidence and geological implications
}

\author{
A CARPINTERI ${ }^{1, *}$, G LACIDOGNA $^{1}$, O BORLA $^{1,2}$, \\ A MANUELLO $^{1}$ and G NICCOLINI ${ }^{3}$ \\ ${ }^{1}$ Politecnico di Torino, Department of Structural Engineering and Geotechnics, \\ Corso Duca degli Abruzzi 24 - 10129 Torino, Italy \\ ${ }^{2}$ National Institute of Nuclear Physics, INFN Via Pietro Giuria 1 - 10125 Torino, Italy \\ ${ }^{3}$ National Research Institute of Metrology, INRIM Strada delle Cacce 91 - 10135 \\ Torino, Italy \\ e-mail: alberto.carpinteri@polito.it
}

\begin{abstract}
It has been observed energy emission in the form of electromagnetic radiation, clearly indicating charge redistribution, and neutron bursts, necessarily involving nuclear reactions, during the failure process of quasi-brittle materials such as rocks, when subjected to compression tests. The material used is Luserna stone, which presents a very brittle behaviour during compression failure. The observed phenomenon of high-energy particle emission, i.e., electrons and neutrons, can be explained in the framework of the superradiance applied to the solid state, where individual atoms lose their identity and become part of different plasmas, electronic and nuclear. Since the analysed material contains iron, it can be conjectured that piezonuclear reactions involving fission of iron into aluminum, or into magnesium and silicon, should have occurred during compression damage and failure. These complex phenomenologies are confirmed by Energy Dispersive X-ray Spectroscopy (EDS) tests conducted on Luserna stone specimens, and found additional evidences at the Earth's Crust scale, where electromagnetic and neutron emissions are observed just in correspondence with major earthquakes. In this context, the effects of piezonuclear reactions can be also considered from a geophysical and geological point of view.
\end{abstract}

Keywords. Brittle failure; acoustic emission; electromagnetic emission; neutron measurements; piezonuclear reactions; element evolution.

\section{Introduction}

It is possible to demonstrate experimentally that the failure phenomena, in particular when they occur in a brittle way, i.e., with a mechanical energy release, emit additional forms of energy related to the fundamental natural forces.

*For correspondence 
The authors have found increasing experimental evidence that energy emission of different forms occurs from solid-state fractures. The tests were carried out at the Laboratory of Fracture Mechanics of the Politecnico di Torino, Italy. By subjecting quasi-brittle materials such as granitic rocks to compression tests, for the first time the bursts of neutron emission during the failure process is observed (Carpinteri et al 2009a, b; Cardone et al 2009), necessarily involving nuclear reactions, besides the well-known acoustic emission (AE) (Mogi 1962; Lockner et al 1991; Ohtsu 1996; Scherbatov \& Turcotte 2003, Carpinteri et al 2006a, b; 2007; 2009c, d, e), and the phenomenon of electromagnetic radiation (EM) (Scott et al 2004, Lacidogna et al 2010, 2011), which is highly suggestive of charge redistribution during material failure and at present under investigation.

Finding convincing explanations of all these complex phenomenologies is still an open issue. EM emission was initially explained in terms of charge separation occurring across the fractures, even if no reasonable explanation is found for each crack face to obtain a net charge (Miroshnichenko \& Kuksenko 1980; O’Keefe \& Thiel 1995). More recently, a model preserving the charge neutrality of crack surfaces, where lines of positive ions on both newly created fracture surfaces oscillate around their equilibrium position in opposite phase to the negative ones, was proposed (Frid et al 2003, Rabinovitch et al 2007).

As for the observed phenomenon of high-energy particle emission, i.e., electrons and neutrons, searching the literature, the authors found very few references, among them a note by Preparata (1991) in the framework of the superradiance applied to the solid state, where individual atoms lose their identity and become part of different plasmas, electronic, nuclear, etc. He discussed the possibility to produce the neutron bursts concomitantly with crack formation in Ti-deuterides. According to this picture, charge separation, which is responsible for EM emission, should be generated by the different accelerations of negative particles, the electrons, and positive ones, the ions, much heavier.

However, our experiments (Carpinteri et al 2009a, b; Cardone et al 2009) follow a different path with respect to the other research teams, where only fissionable or light elements (deuterium) were used, in pressurized gaseous media (Arata et al 1995, 2002), in liquids with ultrasounds and cavitation (Taleyarkhan 2002), as well as in solids with shock waves and fracture (Diebner 1962; Kaliski 1976, 1978; Winterberg 1984; Derjaguin et al 1989; Fujii et al 2002). We are treating with inert, stable and non-radioactive elements at the beginning of the experiments (iron) (Carpinteri et al 2009a, b; Cardone et al 2009), as well as after the experiments (aluminum). Neither radioactive wastes, nor gamma emissions were recorded, but only thermal and fast neutron emissions. As confirmation of this observation, the results of Energy Dispersive X-ray Spectroscopy (EDS), performed on samples coming from the Luserna stone, a metamorphic rock deriving from a granitoid protolith, specimens used in the experiments (Carpinteri et al 2009a, b; Cardone et al 2009), show that, on the fracture surfaces, a considerable reduction in the iron content $(\sim 25 \%)$ is counterbalanced by an increase in $\mathrm{Al}, \mathrm{Si}$ and $\mathrm{Mg}$ concentrations (Carpinteri et al 2011a).

The experimental analysis carried out by the authors may open a new possible scenario, in which the coherent EM fields are able to produce neutron bursts in presence of sudden stressdrops or catastrophic fractures, where charged-particle acceleration may take place.

\section{Electromagnetic emission measurements}

Crack growth is accompanied by acoustic emission ultrasonic waves (AE) and electromagnetic emission (EME). We measured the magnetic field, given by the moving charges, in the 
low-frequency range during laboratory fracture experiments on granitic rocks specimens loaded up to failure (Lacidogna et al 2011; Carpinteri et al 2011b; Warwick et al 1982).

Four cylindrical Luserna stone specimens were examined (figure 1). The electromagnetic signals were detected using a device (Narda ELT-400 exposure level tester) calibrated according to metrological requirements. The adopted device works in the frequency range between $10 \mathrm{~Hz}$ and $400 \mathrm{kHz}$, the measurement range is between $1 \mathrm{nT}$ and $80 \mathrm{mT}$, and the three-axial measurement system has a $100 \mathrm{~cm}^{2}$ magnetic field sensor for each axis. This particular frequency range was chosen to avoid disturbances due to radio waves that operate on medium frequencies of $300-3000 \mathrm{kHz}$, or other electronic devices that generally operate on frequencies above 5-30 MHz.

The tests were carried out by means of a servo-hydraulic press, with a maximum capacity of $1800 \mathrm{kN}$, working by a digital type electronic control unit. The management software was TESTXPERTII by Zwick/Roel (Zwick/Roel Group, Ulm, Germany), while the mechanical parts are manufactured by Baldwin (Instron Industrial Products Group, Grove City, PA, USA). The force applied was determined by measuring the pressure in the loading cylinder by means of a transducer. The margin of error in the determination of the force is $1 \%$, which makes it a class 1 mechanical press. The specimens were arranged with the two smaller surfaces in contact with the press platens, without coupling materials in-between, according to the testing modalities known as 'test by means of rigid platens with friction'. During the compression tests Narda ELT-400 device was placed $1 \mathrm{~m}$ away from the specimens.

Specific tests were conducted to assess the potential EM environmental noise, and what affecting the EM signals due to the MTS test machine electronic control. In particular, the EM probe was used to detect the EM background noise for about $5 \mathrm{~h}$ before the beginning of each compressive test. The background noise was estimated at about $40 \mathrm{nT}$ in the frequency range $10 \mathrm{~Hz}-400 \mathrm{kHz}$. Data acquisition of the EME signals was triggered when the magnetic field exceeded the threshold fixed at $0.2 \mu \mathrm{T}$, after the preliminary measurements to filter out the magnetic noise in the laboratory.

The shapes and sizes of the specimens, and the employed piston velocity are listed in table 1 . The selected piston velocity, reported in the table, is in the authors' experience the most suitable value to evaluate $\mathrm{AE}$ and EME activity in quasi-brittle materials such as concrete and rocks (Carpinteri et al 2006a, b, 2007; Lacidogna et al 2011; Carpinteri et al 2011b).
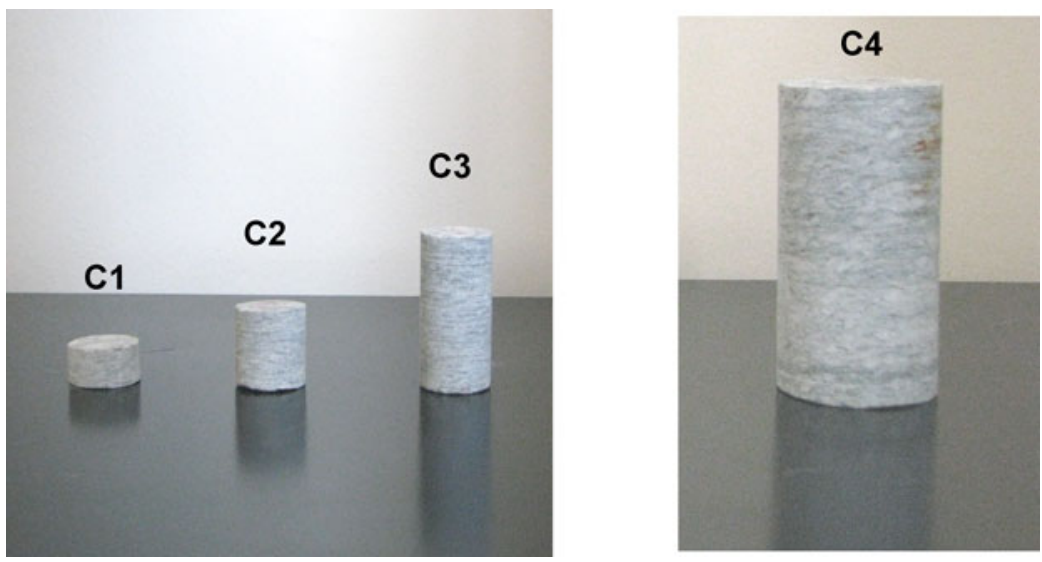

Figure 1. The cylindrical Luserna stone specimens $\mathrm{C} 1, \mathrm{C} 2, \mathrm{C} 3$ and $\mathrm{C} 4$ utilized for EM tests. 
Table 1. Geometry of the cylindrical Luserna stone specimens and compression test piston velocities.

\begin{tabular}{lcccc}
\hline Specimen & $\begin{array}{c}\text { Diameter } \\
(\mathrm{mm})\end{array}$ & $\begin{array}{c}\text { Height } \\
(\mathrm{mm})\end{array}$ & $\begin{array}{c}\text { Slenderness } \\
\lambda=\mathrm{H} / \mathrm{D}\end{array}$ & $\begin{array}{c}\text { Piston velocity } \\
(\mathrm{mm} / \mathrm{s})\end{array}$ \\
\hline $\mathrm{C} 1$ & 28 & 14 & 0.5 & 0.001 \\
$\mathrm{C} 2$ & 28 & 28 & 1 & 0.001 \\
$\mathrm{C} 3$ & 28 & 56 & 2 & 0.001 \\
$\mathrm{C} 4$ & 53 & 100 & 2 & 0.001 \\
\hline
\end{tabular}

As can be seen from table 1, the first three specimens (C1-3) have the same diameter $(28 \mathrm{~mm})$ with a different slenderness $\lambda$, respectively of $0.5,1$ and 2 , specimen $\mathrm{C} 4$ has a diameter equal to $53 \mathrm{~mm}$ and slenderness $\lambda=2$. During the compression tests, all the specimens have shown a brittle response, with a rapid decrease in load-carrying capacity beyond the peak load. In figures 2-5, the load vs. time diagrams and the EM signals are reported for specimens C1-4. As shown in figures $2-5$, the mechanical behaviour of specimens is characterized by a complex load vs. time diagram. This is due to the composition of Luserna stone, which is a natural and heterogeneous material.

Specimen C1 presents a more ductile behaviour (figure 2) characterized by the descending branch of the load vs. time diagram. During the compression test, three EM signals, with constant peak amplitude of $1.2 \mu \mathrm{T}$, were detected at $180 \mathrm{~s}, 500 \mathrm{~s}$ and $750 \mathrm{~s}$ (see figure 2a). All these signals were anyway detected at stress-drops, in figure $2 \mathrm{~b}$ also the amplitude and FFT analysis of the
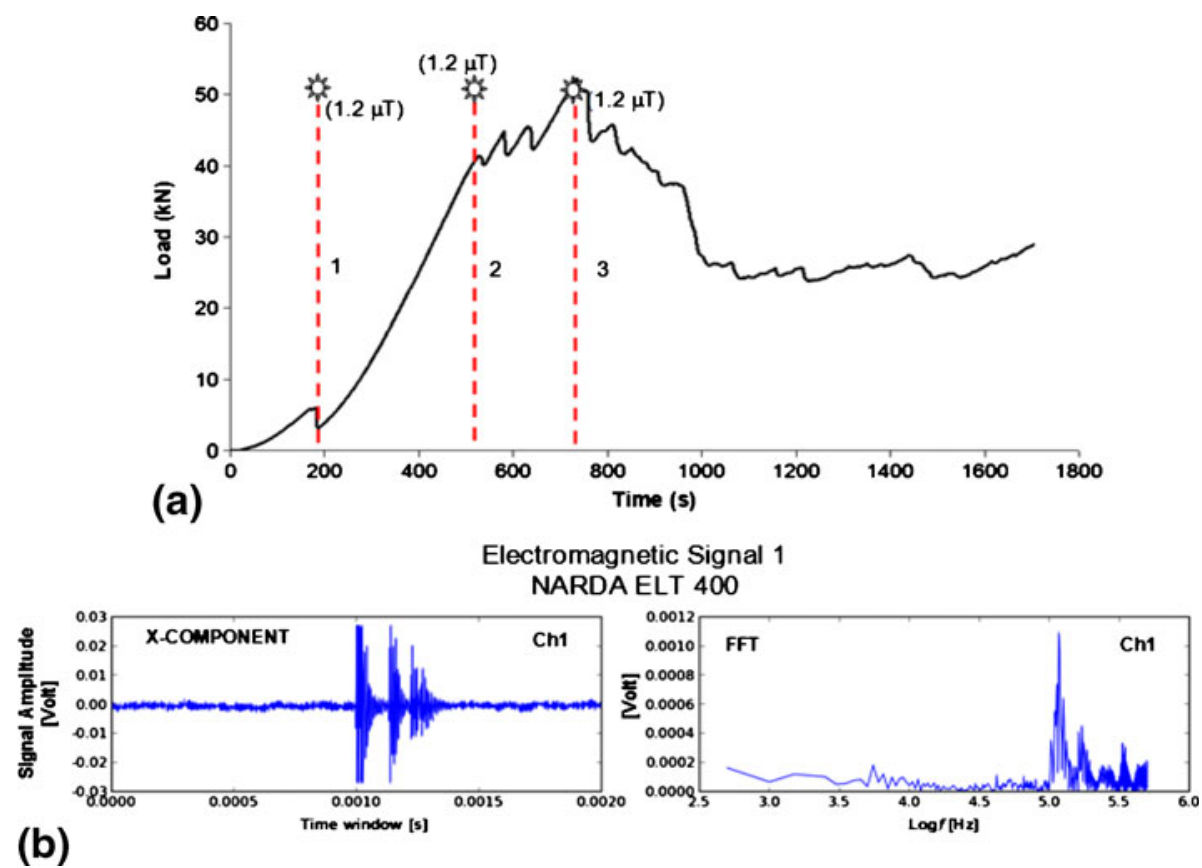

Figure 2. (a) Load vs. time diagram of the Luserna stone specimen C1. (b) Amplitude and FFT analysis for the detected signal 1 . 


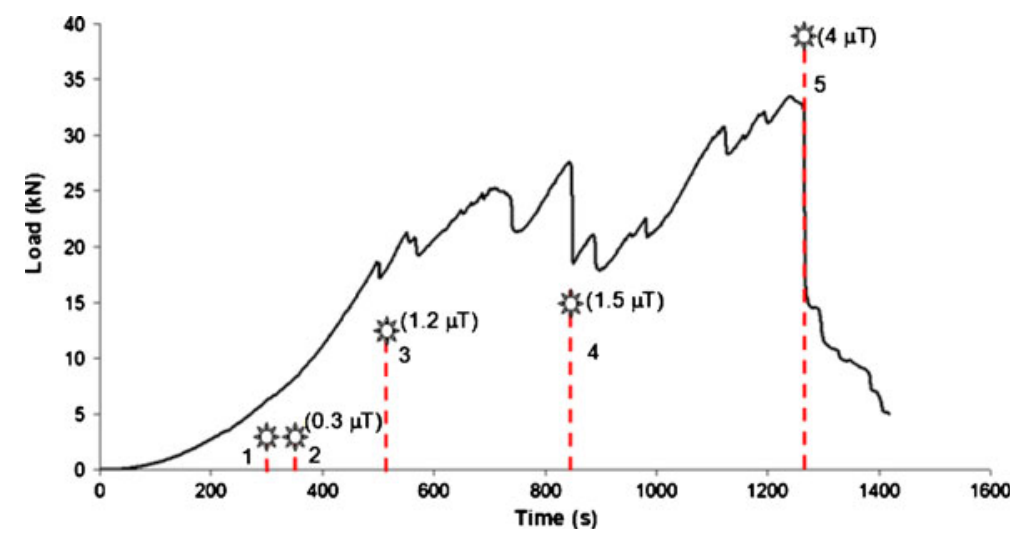

Figure 3. Load vs. time diagram of the Luserna stone specimen C2. Five EM signals were detected during the test.

first EME signal of the test on specimen $\mathrm{C} 1$ are shown. During the post-peak stage, i.e., the softening branch in the load vs. time diagram, no further EME signals were detected. In fact, at the peak load the fracture is completely formed and the subsequent stages are characterized only by opening of the fracture surfaces. According to the model proposed by Frid et al (2003) and Rabinovitch et al (2007), this means that no newly broken atomic bonds can contribute to EME. In figure $2 b$ the FFT analysis for signal 1 is shown. The main detected frequency is close to $160 \mathrm{kHz}$ according to the working frequency range of the Narda ELT-400.

Otherwise, specimens C2 and C3 show a very brittle behaviour, characterized by abrupt stress drops after reaching the peak load. The experimental results are reported in figures 3 and 4 . Five EM signals were detected during the specimen C2 test. In specimen C3, four EM signals were observed. Only in the case of specimen C2, the signal amplitudes (in $\mu \mathrm{T}$ ) seem to be proportional to the stress-drop values, as reported in (Fukui et al 2005). Specimen C4 presents a very high amplitude EME $(16 \mu \mathrm{T})$ in correspondence of a stress drop localized at $1420 \mathrm{~s}$ after the

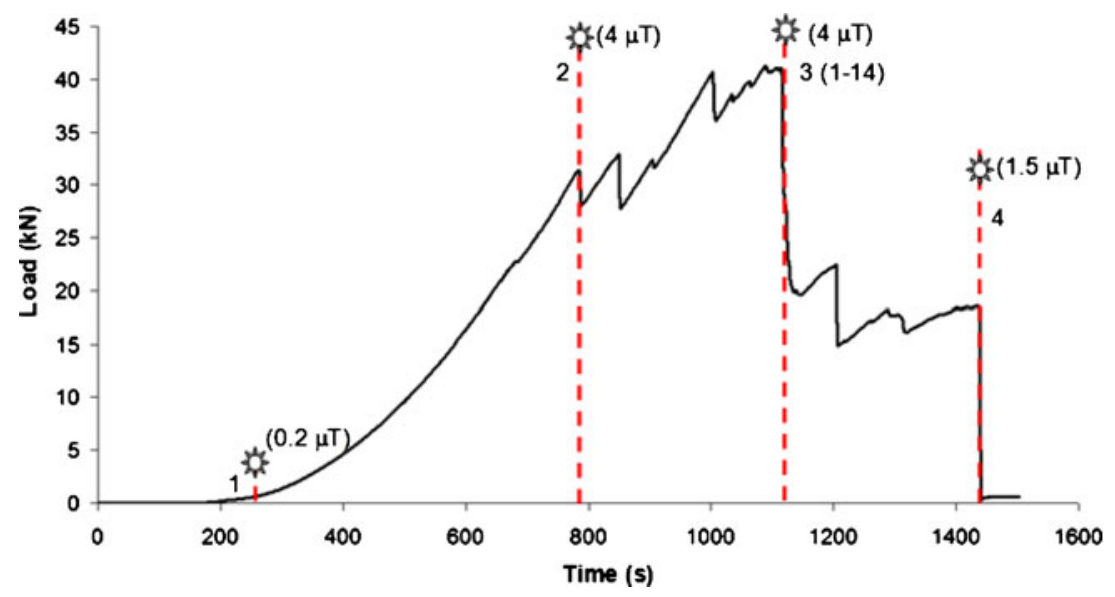

Figure 4. Load vs. time diagram of the Luserna stone specimen C3. Four EM signals were detected during the test. 


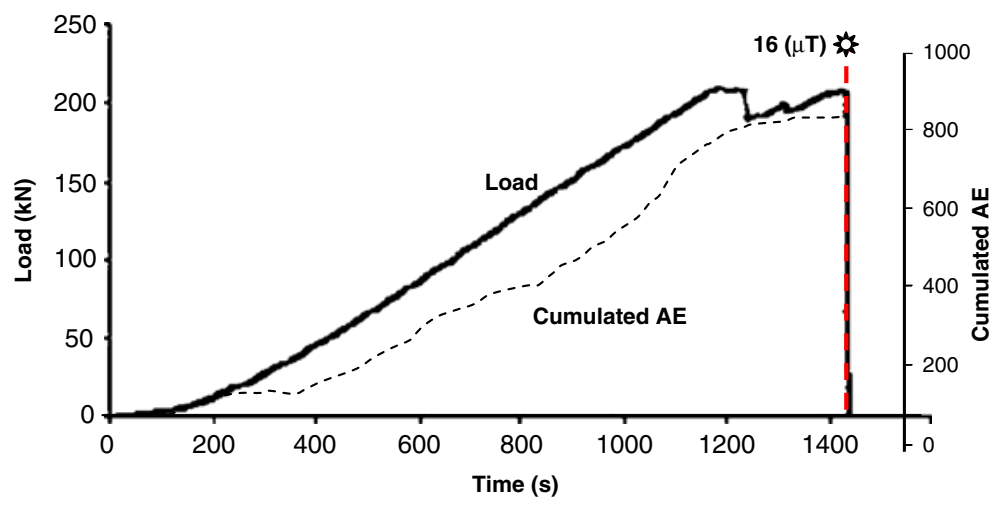

Figure 5. Load vs. time diagram and AE cumulated number (dashed line) for specimen C4. A signal of $16 \mu \mathrm{T}$ is detected in correspondence to the peak load.

beginning of the test. In this case, a very brittle behaviour is observed and the EME is localized in correspondence of the failure of the specimen. Also the cumulated number of AE is detected during the compression test (see figure 5). The experimental results obtained in the described test are in good agreement with those obtained in Lacidogna et al (2011) and Carpinteri et al (2011b).

As shown in figures 2-5, a correlation between EME signal amplitudes and stress drops does not result for all specimens. This is probably due to the anisotropical distribution of the impulsive EME fields around the specimens. Thus, the single Narda ELT-400 device adopted for EME signals detection, placed $1.0 \mathrm{~m}$ away from the specimens during the compression tests, is not expected to capture all EME events generated by the source cracks. This problem could be avoided by using a suitable array of EME probes placed around the test specimens. Interestingly, even taking a single device, a proportionality relation between detected EME signals and related stress drops is found considering all the signals detected on the tested specimens and the related stress drop values.

Recently, the experimental set up for data acquisition has been optimized, by measuring the magnetic flux passing through the surface of a conducting coil which rings the specimen. In this way, all EME signals emitted by the specimen in the frequency range $160 \mathrm{kHz}-5 \mathrm{MHz}$ can be detected in order to study systematically the correlation signal amplitude vs. stress drop. A technical description of this device, realized at the National Research Institute of Metrology -INRIM- in Torino, is reported in Lacidogna et al (2010).

Based on the authors' experience gained in numerous laboratory tests, it is interesting to note that, despite their different mechanical behaviour, all the specimens composed by brittle or quasi-brittle materials, as rocks or concrete, generate EME only during sharp drops in stress (Lacidogna et al 2011; Carpinteri et al 2011b; Fukui et al 2005). These sharp stress drops are due to a rapid decay of the material mechanical properties, generated by the formation of new micro-cracks during the loading process. Indeed, as has been shown by Carpinteri (1986, 1989, 1990, 1994), and by Hudson et al (1972), the energy release modalities during compressive tests depend on the intrinsic brittleness of the material of the test specimens, as well as on test specimen dimensions and slenderness.

This evidence enables the investigation EM signals as collapse precursors in materials such as rocks and concrete. Furthermore, the observed electromagnetic activity from laboratory 
experiments looks very promising for effective applications at the geophysical scale (O'Keefe \& Thiel 1995; Warwick et al 1982).

As a matter of fact, the 5 EME signals shown in figure 3 are spread over a $1400 \mathrm{~s}$ test duration. Reasonably, it can be assumed that the time intervals between consecutive EME events, or waiting times, became longer if the duration of the experiment would be incresed (e.g. by reducing the piston velocity of the mechanical press). Since the elastic energy in the Earth's crust is stored over years or decades, we should observe EME seismic precursors some weeks or months before an earthquake. An analogous phenomenon has been described for waiting-time distributions in acoustic emission and earthquake time series. It has been shown that the structural damage, monitored by AE technique, and the seismic events, occurred in the region during the monitoring period, are described by a unique scaling law indicating self-similarity over a wide range of magnitude scales (Niccolini et al 2009, 2010, 2011).

Obviously, there exist evident differences between laboratory experiments and natural conditions. For example, natural rocks contain water which increases the electrical conductivity, while rock specimens have lost most of their water content. Furthermore, the uniaxial stresses applied during laboratory tests does not correctly model the stress fields acting on rocks embedded in the Earth's crust. However, as already mentioned in the Introduction, it has been observed $\mathrm{AE}$ in low- and high-frequency range, and EME during damage and failure of different kind of rocks. This encourages the investigation of seismic precursors. In particular, the change in the frequency spectra and the amplitudes of released signals during the different stages of damage could provide information about the time occurrence, and even the magnitude, of possible impending earthquakes. Moreover, by means of a network of monitoring stations, it could be possible also to localize the hypocentre.

\section{Neutron emission measurements}

Classically during the process of nuclear fission, a neutron strikes a heavy nucleus that splits into two lighter fragments. Each of the two fragments consists of a nucleus with roughly half the neutrons and protons of the original nucleus. This fission process releases a large amount of energy and gamma rays are emitted as well as two or more neutrons that are no longer bound by the fission fragments.

Instead piezonuclear fission reactions consist in new nuclear reactions produced by new methods such as pressure, fracture or cavitation. Even small deviations from classical assumptions, e.g., from the concept of average bond energy per nucleon, could explain these new phenomena. It would suffice to assume a weak section within the nucleus, as it happens in very hard and strong rocks, that nevertheless cleave under very low stresses. Moreover, the main and peculiar characteristic of piezonuclear reactions is neutron production without gamma emission. This physical phenomenon could be the signature of a new physics of nuclear interactions, as it is theoretically and experimentally discussed in the literature (Carpinteri et al 2009a, b; Cardone et al 2009).

Similar to the preliminary piezonuclear tests presented in Carpinteri et al (2009a, b) and Cardone et al (2009), the material used for the tests is non-radioactive Green Luserna stone. In these new experiments, nine Green Luserna stone cylindrical specimens with different size and slenderness, denoted with P1, P2,.., P9 (figure 6, table 2), were used in order to assess neutron emissions related to specimens with very brittle or catastrophic failure (Carpinteri 1989, 1990). In particular, specimen P6 (indicated as C4 in the previous section) has been monitored by EM 


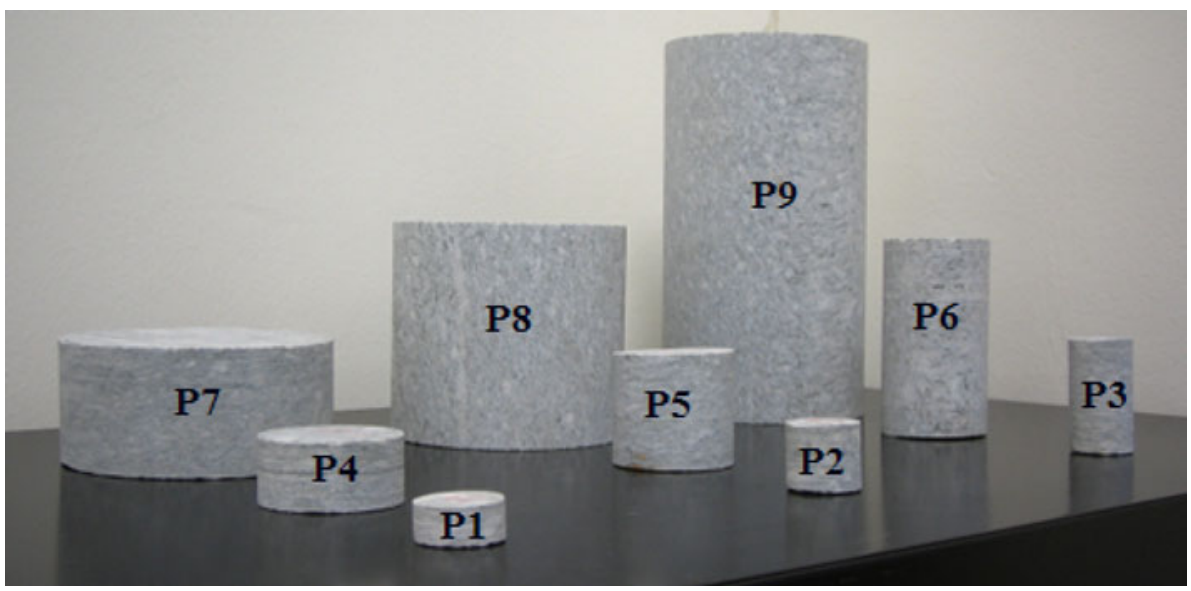

Figure 6. Luserna stone cylindrical specimens, by varying slenderness and size-scale.

and $\mathrm{AE}$ devices in order to analyse electromagnetic, acoustic and neutron emissions during the same test (see figure 5).

Also, these compression tests were performed with a planned displacement rate ranging from 0.001 to $0.01 \mathrm{~mm} / \mathrm{s}$, by means of the same servo-hydraulic press described in the previous section. The neutron detector used in the tests is a $\mathrm{He}^{3}$ type with electronic of preamplification, amplification and discrimination, directly connected to the detector tube, which is of the type referred to as 'long counter'. This detector was calibrated for the measurement of thermal neutrons; its sensitivity is $65 \mathrm{cps} / \mathrm{n}_{\text {thermal }}( \pm 10 \%$ declared by the factory) i.e., the flux of thermal neutrons was 1 thermal neutron $/ \mathrm{s} \mathrm{cm}^{2}$, corresponding to a count rate of $65 \mathrm{cps}$. The $\mathrm{He}^{3}$ neutron detector was switched on at least one hour before the beginning of each compression test, in order to reach the thermal equilibrium of electronics, and to make sure that the behaviour of the devices was stable with respect to intrinsic thermal effects. The detector was placed in front of the test specimen at a distance of $20 \mathrm{~cm}$ and it was enclosed in a polystyrene case of $10 \mathrm{~cm}$ of thickness in order to avoid 'spurious' signals coming from impact and vibration.

A relative measurement of natural neutron background was performed in order to assess the average background affecting data acquisition in experimental room condition. The $\mathrm{He}^{3}$ device

Table 2. Characteristics of compression tests under monotonic loading on Luserna stone specimens.

\begin{tabular}{|c|c|c|c|c|c|c|}
\hline \multirow{2}{*}{$\begin{array}{l}\text { Granite } \\
\text { Specimen }\end{array}$} & \multicolumn{3}{|c|}{ Geometry of the specimen } & \multirow{2}{*}{$\begin{array}{c}\text { Displacement } \\
\text { velocity }(\mathrm{mm} / \mathrm{s})\end{array}$} & \multirow{2}{*}{$\begin{array}{l}\text { Peak load } \\
(\mathrm{kN})\end{array}$} & \multirow{2}{*}{$\begin{array}{l}\text { Time at the } \\
\text { peak load }(\mathrm{s}\end{array}$} \\
\hline & $\mathrm{D}(\mathrm{mm})$ & $\mathrm{H}(\mathrm{mm})$ & $\lambda=\mathrm{H} / \mathrm{D}$ & & & \\
\hline $\mathrm{P} 1$ & 28 & 14 & 0.5 & 0.001 & 52.19 & 735.0 \\
\hline $\mathrm{P} 2$ & 28 & 28 & 1 & 0.001 & 33.46 & 1239.0 \\
\hline P3 & 28 & 56 & 2 & 0.001 & 41.28 & 1089.0 \\
\hline $\mathrm{P} 4$ & 53 & 25 & 0.5 & 0.001 & 129.00 & 960.0 \\
\hline P5 & 53 & 50 & 1 & 0.001 & 139.10 & 2460.0 \\
\hline P6 & 53 & 101 & 2 & 0.001 & 206.50 & 1180.0 \\
\hline P7 & 112 & 60 & 0.5 & 0.01 & 1099.30 & 231.3 \\
\hline P8 & 112 & 112 & 1 & 0.01 & 1077.10 & 263.5 \\
\hline P9 & 112 & 224 & 2 & 0.01 & 897.80 & 218.6 \\
\hline
\end{tabular}


Table 3. Compression tests under monotonic loading control. Neutron emissions experimental data on Luserna stone specimens.

\begin{tabular}{lcccc}
\hline $\begin{array}{l}\text { Granite } \\
\text { Specimen }\end{array}$ & $\begin{array}{c}\mathrm{D} \\
(\mathrm{mm})\end{array}$ & $\lambda=\mathrm{H} / \mathrm{D}$ & $\begin{array}{c}\text { Average } \\
\text { neutron } \\
\text { background } \\
\left(10^{-2} \mathrm{cps}\right)\end{array}$ & $\begin{array}{c}\text { Count rate } \\
\text { at the neutron } \\
\text { emission } \\
\left(10^{-2} \mathrm{cps}\right)\end{array}$ \\
\hline P1 & 28 & 0.5 & $3.17 \pm 0.32$ & $8.33 \pm 3.73$ \\
P2 & 28 & 1 & $3.17 \pm 0.32$ & background \\
P3 & 28 & 2 & $3.17 \pm 0.32$ & background \\
P4 & 53 & 0.5 & $3.83 \pm 0.37$ & background \\
P5 & 53 & 1 & $3.84 \pm 0.37$ & $11.67 \pm 4.08$ \\
P6 & 53 & 2 & $4.74 \pm 0.46$ & $25.00 \pm 6.01$ \\
P7 & 112 & 0.5 & $4.20 \pm 0.80$ & background \\
P8 & 112 & 1 & $4.20 \pm 0.80$ & $30.00 \pm 11.10$ \\
P9 & 112 & 2 & $4.20 \pm 0.80$ & $30.00 \pm 10.00$ \\
\hline
\end{tabular}

was positioned in the same condition of the experimental set-up and the background measures were performed fixing at $60 \mathrm{~s}$ the acquisition time, during a preliminary period of more than three hours, for a total number of 200 counts. The average measured background level is ranging from $(3.17 \pm 0.32) \cdot 10^{-2}$ to $(4.74 \pm 0.46) \cdot 10^{-2}$ cps (see tables 2 and 3 ).

Additional background measurements were repeated before each test, fixing an acquisition time of $60 \mathrm{~s}$, up to the assessment of no significant variation in natural background. Neutron measurements of specimens P2, P3, P4, P7 yielded values comparable with the ordinary natural background, even at the peak load, whereas for specimens Pl and P5, the experimental data exceeded the background value by about four times. In the case of the specimens P6, P8 and P9, the neutron emissions achieved values from five to ten times higher than the ordinary background. In figure 7, the load vs. time diagram and the neutron count rate evolution for specimens P6, P8 and P9 are shown. In table 3, the experimental data concerning compression tests on the nine Luserna stone specimens are summarized.

In the preliminary tests mentioned above, Luserna stone prisms, measuring $6 \times 6 \times 10=$ $360 \mathrm{~cm}^{3}$ and characterized by very brittle failure, were tested in compression (Carpinteri et al 2009a, b; Cardone et al 2009). The preliminary experimental results are confirmed by those obtained from compression tests on the cylindrical specimens presented in this paper. Neutron emissions related to specimens with very brittle or catastrophic failure result to be larger by about one order of magnitude than the ordinary background (see figure 7).

It is also interesting to note that, in spite of specimen dimensions and slenderness, EME have been detected in correspondence of sharp stress drops during all the compressive tests (see section 2 and figures 2-5), while, neutron emissions are observed only for specimens with a volume greater than a certain threshold and therefore presenting a very brittle failure. In figure 7a, the results obtained from the catastrophic failure of the Luserna stone test specimen P6, which has a volume of about $233 \mathrm{~cm}^{3}$, are presented. As mentioned in the previous section, specimen P6 (named $\mathrm{C} 4$ in table 1 and figure 5) has been monitored not only using the $\mathrm{He}^{3}$ neutron detector, but also by means of the AE and EM emission devices. Very high EME amplitude $(16 \mu \mathrm{T})$ and neutron emission (of about five times the neutron background level) were observed concomitant with the sharp stress drop at the time of failure (see figures 5 and $7 \mathrm{a}$ ).

Moreover, once again the maximum neutron emissions were obtained from test specimens with a volume larger than a threshold value of about $360 \mathrm{~cm}^{3}$ (see figure $7 \mathrm{~b}, \mathrm{c}$ ). 

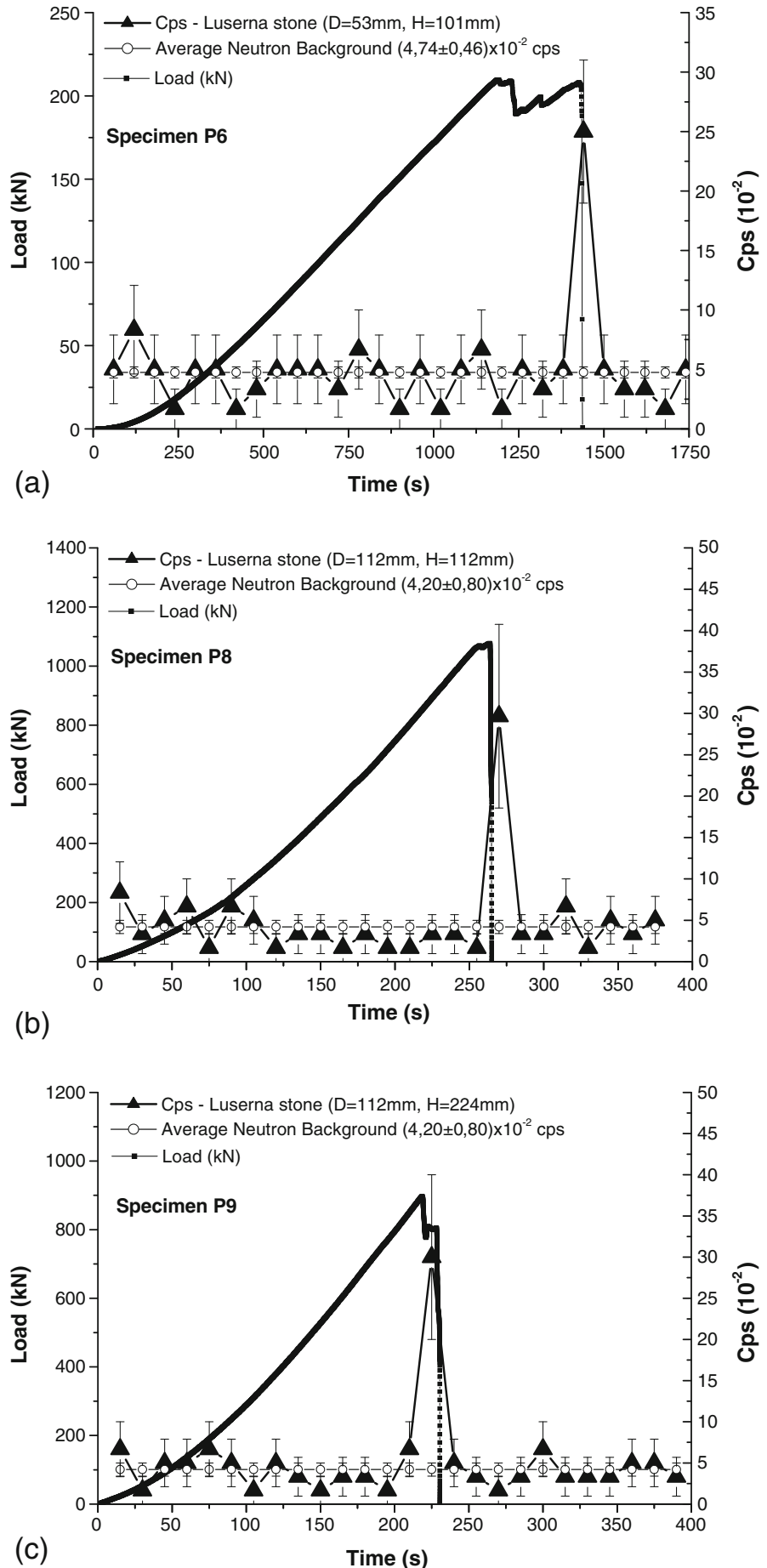

Figure 7. Specimens P6, P8, P9: Load vs. time diagrams, and neutron emissions count rate. 
From the authors' actual knowledge, the experimental results show that a volume approximately exceeding $200 \mathrm{~cm}^{3}$, combined with the extreme brittleness of the tested material, represents a critical threshold value for a neutron emission of about one order of magnitude higher than the ordinary background. It appears that this correlation arises because larger specimen volume implies higher probability of finding larger size flaws which when propagating would result in larger stress drops.

As we have already mentioned in section 2, due to the difficulties in neutron measurements in presence of an electromagnetic field, the electromagnetic emissions were also monitored during further compression tests by using a measuring device specially designed at the National Research Institute of Metrology -INRIM- in Torino, to analyse the working frequency range from few $\mathrm{Hz}$ up to several $\mathrm{MHz}$ (Lacidogna et al 2010).

The experimental results show that the typical EME detected during the tests are included in the frequency range from $160 \mathrm{kHz}$ to $5 \mathrm{MHz}$ (Lacidogna et al 2010). The $\mathrm{He}^{3}$ neutron detector, is designed and manufactured under a quality system in compliance with the standard requirements provided by the International Electrotechnical Commission for EMI (Electro Magnetic Interference). In particular, this device is not sensitive to electromagnetic noise in the frequency range from $150 \mathrm{kHz}$ to $230 \mathrm{MHz}$. Owing to the good immunity to electromagnetic disturbances, it can be demonstrated that no spurious neutron counts were detected.

Energy Dispersive X-ray Spectroscopy (EDS) was performed on different samples of external or fracture surfaces belonging to granite specimens used in the piezonuclear tests (Carpinteri et al 2009a, b; Cardone et al 2009). For each sample, different measurements of the same crystalline phases (phengite or biotite) were performed in order to get averaged information of its chemical composition and to detect possible piezonuclear transmutations from iron to lighter elements. Considering the results for phengite and biotite, and also their abundances in the Luserna stone composition, a considerable reduction in the iron content $(\sim 25 \%)$ is observed. This iron decrease is consistently counterbalanced by an increase in aluminum, silicon and magnesium. In particular, the increase in aluminum content corresponds to $85 \%$ of the iron decrease (Carpinteri et al 2011a). Therefore, the following piezonuclear fission reactions should have occurred in granitic rocks during the piezonuclear tests (Carpinteri et al 2009a, b; Cardone et al 2009; Carpinteri \& Manuello 2011):

$$
\begin{gathered}
\mathrm{Fe}_{26}^{56} \rightarrow 2 \mathrm{Al}_{13}^{27}+2 \text { neutrons } \\
\mathrm{Fe}_{26}^{56} \rightarrow \mathrm{Mg}_{12}^{24}+\mathrm{Si}_{14}^{28}+4 \text { neutrons. }
\end{gathered}
$$

\section{Electromagnetic and neutron emissions at the scale of the Earth's crust}

It has been recently reported that electromagnetic phenomena take place in a wide frequency range prior to an earthquake, and these precursory seismo-electromagnetic effects are expected to be useful for the mitigation of earthquake hazards (Parrot 1994; Fraser-Smith et al 1990). The generation of electromagnetic emissions during earthquakes has been verified also in laboratory experiments involving fracturing of quartz-bearing rocks (Gokhberg et al 1982; Warwick et al 1982; Nitsan 1977; Ogawa et al 1985; Yamada et al 1989; Enomoto \& Hashimoto 1994).

Similar to the case of EME coming from fracture phenomena, the neutron emissions involved in piezonuclear reactions have been detected not only in laboratory experiments but also at the Earth's crust scale. Recent neutron emission detections by Kuzhevskij et al (2003a, b) have led 
to consider also the Earth's crust, in addition to cosmic rays, as being a relevant source of neutron flux variations. Neutron emissions measured near the Earth's surface exceeded the neutron background by more than three orders of magnitude in correspondence to seismic activity and rather appreciable earthquakes (Volodichev et al 2000). This relationship between the processes in the Earth's crust, EM emissions and neutron flux variations has allowed to develop new methods for short-term prediction and monitoring of earthquakes (Kuzhevskij et al 2003a, b; Parrot 1994; Fraser-Smith et al 1990).

Taking into account that granite is a common and widely occurring type of intrusive, sialic, igneous rock, and that it is characterized by an extensive concentration in the rocks that make up the Earth's crust ( $\sim 60 \%$ of the Earth's crust), the piezonuclear fission reactions considered above can be generalized from the laboratory to the Earth's crust scale, where mechanical phenomena of brittle fracture, due to fault collision and subduction, take place continuously in the most seismic areas of the globe. This hypothesis seems to find surprising evidence and confirmation from both the geomechanical and the geochemical points of view (Carpinteri \& Manuello 2011).

The present natural abundances of aluminum $(\sim 8 \%)$, silicon $(\sim 28 \%)$ and magnesium $(\sim 1.3 \%)$ and scarcity of iron $(\sim 4 \%)$ in the continental Earth's crust (Favero \& Jobstraibizer 1996; Taylor \& McLennan 1996, 2005) are possibly due to the piezonuclear fission reactions (1 and 2) expressed above (Carpinteri \& Manuello 2011). In addition, considering the percentage mass concentrations of other chemical elements, such as $\mathrm{Na}(\sim 2.9 \%), \mathrm{Ni}(\sim 0.01 \%)$, and Co $(\sim 0.003 \%)$, in the continental crust (Anbar 2008; Fowler 2005; Doglioni 2007; Rudnick \& Fountain 1995), it is possible to conjecture additional piezonuclear fission reactions that could have taken place in correspondence to plate collision and subduction (Carpinteri \& Manuello 2011):

$$
\begin{gathered}
\mathrm{Co}_{27}^{59} \rightarrow \mathrm{Al}_{13}^{27}+\mathrm{Si}_{14}^{28}+4 \text { neutrons, } \\
\mathrm{Ni}_{28}^{59} \rightarrow 2 \mathrm{Si}_{14}^{28}+3 \text { neutrons, } \\
\mathrm{Ni}_{28}^{59} \rightarrow \mathrm{Na}_{11}^{23}+\mathrm{Cl}_{17}^{35}+1 \text { neutron. }
\end{gathered}
$$

The large concentrations of granite minerals, such as quartz and feldspar $\left(\mathrm{SiO}_{2}, \mathrm{Al}_{2} \mathrm{O}_{3}\right)$ in the Earth's crust, and to a lesser extent of magnesite, halite, and zeolite $\left(\mathrm{MgO}, \mathrm{Na}_{2} \mathrm{O}, \mathrm{Cl}_{2} \mathrm{O}_{3}\right)$, and the low concentrations of magnetite, hematite, bunsenite and cobaltite minerals (composed predominantly of $\mathrm{Fe}, \mathrm{Co}$, and $\mathrm{Ni}$ ), could be ascribed to piezonuclear reactions $(1,2,3,4$ and 5) due to tectonic and subduction phenomena (Carpinteri \& Manuello 2011).

\section{Heterogeneity in the composition of the Earth's crust: Fe and Al reservoir localizations}

The localization of $\mathrm{Al}$ and $\mathrm{Fe}$ mineral reservoirs seems to be closely connected to the geological periods when different continental zones were formed (Favero \& Jobstraibizer 1996; Taylor \& McLennan 1996, 2005; Anbar 2008; Fowler 2005; Doglioni 2007; Roy et al 2001; World Iron 2009; World Mineral 2009; Key Iron Dep. 2009). This fact would seem to suggest that our planet has undergone a continuous evolution from the most ancient geological regions, which currently reflect the continental cores that are rich in Fe reservoirs, to more recent or contemporary areas of the Earth's crust where the concentrations of Si and Al oxides present very high mass percentages (Favero \& Jobstraibizer 1996). The main iron reservoir locations (Magnetite \& Hematite mines) are reported in figure $8 \mathrm{a}$. The main concentrations of Al-oxides and rocky andesitic formations 
(the Rocky Mountains and the Andes, with a strong concentration of $\mathrm{Al}_{2} \mathrm{O}_{3}$ minerals) are shown in figure $8 \mathrm{~b}$ together with the most important subduction lines, plate tectonic trenches and rifts (Favero \& Jobstraibizer 1996; Lunine 1998). The geographical locations of main bauxite mines show that the largest concentrations of $\mathrm{Al}$ reservoirs can be found in correspondence to the most seismic areas of the Earth (figure 8b). The main iron mines are instead exclusively located in the oldest and interior parts of continents (formed through the eruptive activity of the proto-Earth), in geographic areas with a reduced seismic risk and always far from the main fault lines. From this point of view, the close correlation between bauxite and andesitic reservoirs and the subduction and most seismic areas of the Earth's crust provides very impressive evidence of piezonuclear effects at the planetary scale.

\section{Geological evidence of piezonuclear reactions}

Evidence of piezonuclear reactions can be also recognized considering the Earth's composition and its evolution throughout the geologic eras. In this way, plate tectonics and the connected

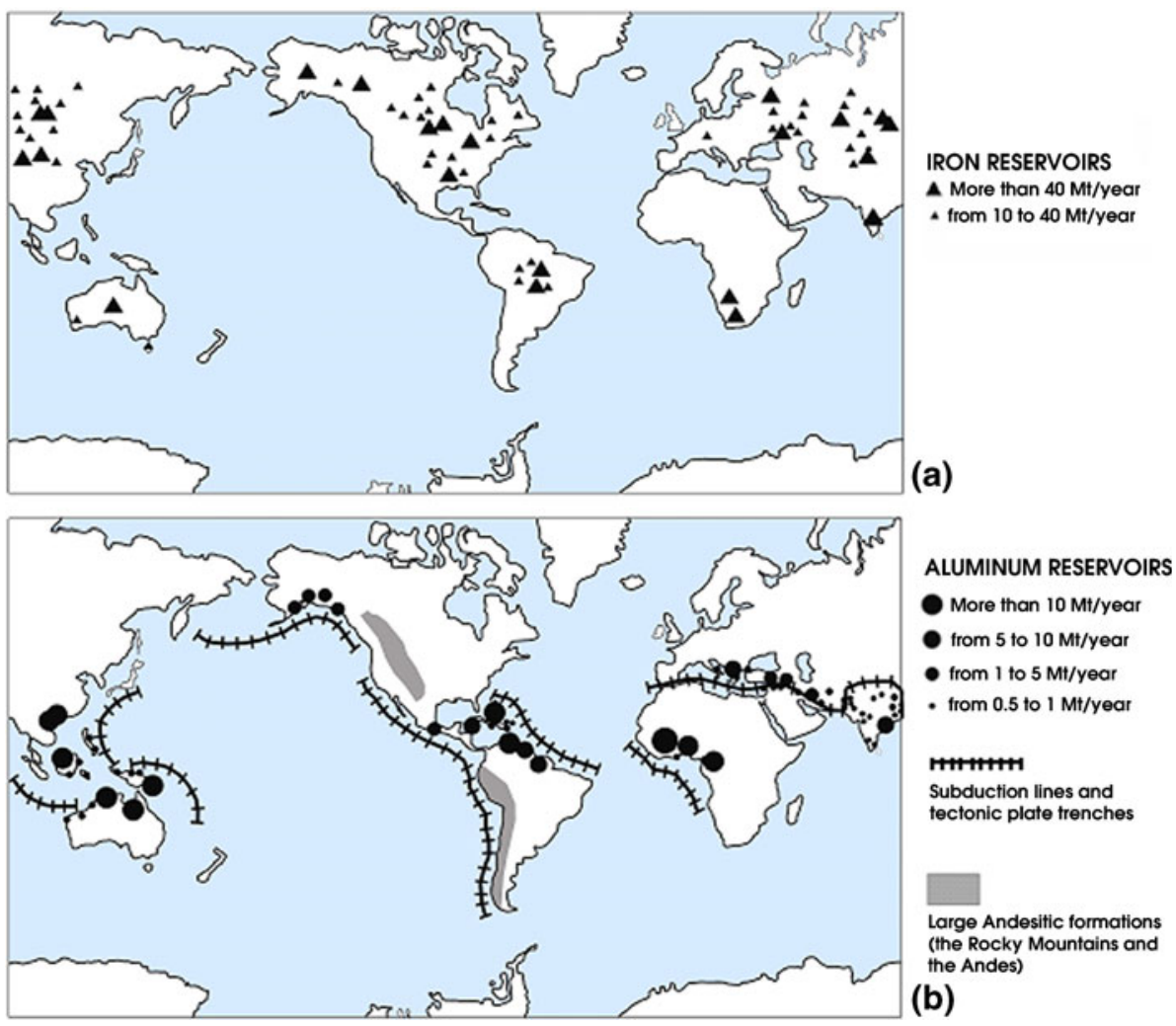

Figure 8. (a) Locations of the largest iron mines in the world (Roy et al 2001; World Iron 2009; World Mineral 2009; Key Iron Dep. 2009). Iron ore reservoirs (Magnetite and Hematite mines) are located in geographic areas with reduced seismic risks and always far from fault lines. (b) The largest aluminum (bauxite) reservoirs are reported together with the main Andesitic formations and most important subduction lines and plate tectonic trenches (Favero \& Jobstraibizer 1996; Lunine 1998). 
plate collision and subduction phenomena are useful to understand not only the morphology of our planet, but also its compositional evolution (Carpinteri \& Manuello 2011).

From 4.0 to 2.0 Gyr ago, Fe could be considered one of the most common bio-essential elements required for the metabolic action of all living organisms (Lunine 1998; Hazen et al 2008; Condie 1976; Canfield 1998; Holland 2006; Kholodov \& Butuzova 2008; Foing 2005; Sigman et al 2004; Galimov 2005; Yamaguchi 2005). Today, the deficiency of this nutrient suggests it as a limiting factor for the development of marine phytoplankton and life on Earth (Anbar 2008; Canfield 1998).

Elements such as $\mathrm{Fe}$ and $\mathrm{Ni}$ in the Earth's protocrust had higher concentrations in the Hadean (4.5-3.8 Gyr ago) and Archean (3.8-2.5 Gyr ago) periods compared to the present values (Favero \& Jobstraibizer 1996; Taylor \& McLennan 2005; Canfield 1998; Holland 2006; Basile-Doelsch et al 2005; Basile-Doelsch 2006; De la Rocha et al 2000; Ragueneau 2000). The Si and Al concentrations instead were lower than they are today (Favero \& Jobstraibizer 1996; Taylor \& McLennan 1996, 2005).

The estimated concentrations of $\mathrm{Fe}, \mathrm{Ni}, \mathrm{Al}$, and $\mathrm{Si}$ in the Hadean and Archean Earth's protocrust and in the Earth's continental crust are reported in figure 9. The data for the Hadean period (4.5-3.8 Gyr ago) are referred to the composition of Earth's protocrust, considering the assumptions made by Foing (2005) and by Taylor \& McLennan (1996, 2005).

According to these authors, the Mars and Moon's crusts are considered to be representative of the composition of the early Earth's protocrust (Hadean Eon) (Taylor \& McLennan 1996, 2005; Foing 2005).

In the same figure, for the Archean period (3.8-2.5 Gyr ago) the data are referred to compositional analysis of Archean sediments (Carpinteri \& Manuello 2011; Taylor \& McLennan 1996, 2005; Favero \& Jobstraibizer 1996; Rudnick \& Fountain 1995; Konhauser et al 2009; Saito 2009; Egami 1975; National Academy of Science 1975; Yaroshevsky, 2006). For the last period from $2.5 \mathrm{Gyr}$ ago to today, the mass percentage concentrations of $\mathrm{Fe}, \mathrm{Ni}, \mathrm{Al}$ and $\mathrm{Si}$ are referred to the present composition of Earth's continental crust (Carpinteri \& Manuello 2011; Taylor \& McLennan 1996, 2005; Favero \& Jobstraibizer 1996; National Academy of Science 1975; Yaroshevsky 2006).

A clear transition from a more basaltic condition (high concentrations of $\mathrm{Fe}$ and $\mathrm{Ni}$ ) to a Sialic one (high concentrations of $\mathrm{Al}$ and $\mathrm{Si}$ ) can be observed during the life time of our planet (Taylor \& McLennan 1996, 2005; Favero \& Jobstraibizer 1996; Doglioni 2007; Rudnick \& Fountain 1995; Konhauser et al 2009; Saito 2009; Egami 1975; National Academy of Science 1975; Yaroshevsky 2006).

The most abrupt changes in element concentrations shown in figure 9 appear to be intimately connected to the tectonic activity of the Earth. The vertical drops in the concentrations of Fe and $\mathrm{Ni}$, as well as the vertical jumps in the concentrations of $\mathrm{Si}$ and $\mathrm{Al}, 3.8 \mathrm{Gyr}$ ago, coincide with the time that many scientists have pointed out as the beginning of tectonic activity on the Earth. The subsequent abrupt transitions 2.5 Gyr ago coincide with the period of the Earth's largest and most intense tectonic activity (Taylor \& McLennan 1996, 2005).

As shown in figure 9, the decrease in the mass concentration of iron and nickel is balanced by the increase in $\mathrm{Al}$ and $\mathrm{Si}$ and assuming an increase in $\mathrm{Mg}$, according to reaction (2), equal to that of $\mathrm{Si}$ over the Earth's lifetime. In the same figure, a total decrease of $\sim 7 \%$ in $\mathrm{Fe}$ and $\mathrm{Ni}$ concentrations and a consistent increase of $\sim 7 \%$ in the lighter chemical element concentrations ( $\mathrm{Mg}, \mathrm{Al}$ and $\mathrm{Si}$ ) between the Hadean period (Hadean Eon, 4.5-3.8 Gyr ago) and the Archean period (Archean Eon, 3.8-2.5 Gyr ago) is shown. Similarly, a decrease of $\sim 5 \%$ in the heavier elements $(\mathrm{Fe}$ and $\mathrm{Ni})$ and a related increase $(\sim 5 \%)$ in the concentrations of lighter ones $(\mathrm{Mg}, \mathrm{Al}$ and $\mathrm{Si}$ ) can be considered between the Archean period (Archean Eon, 3.8-2.5 billion years ago) 


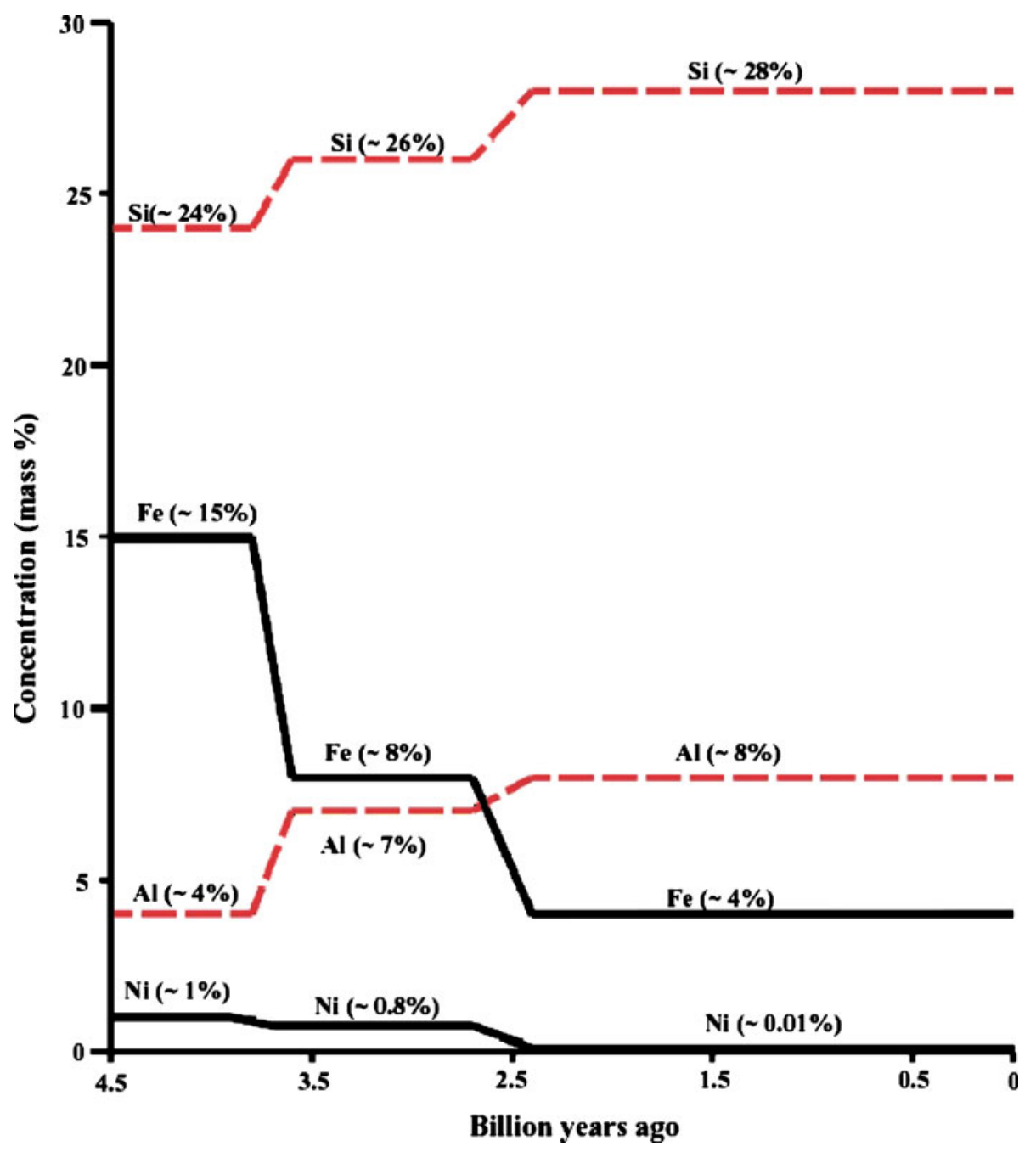

Figure 9. The estimated concentrations of $\mathrm{Fe}, \mathrm{Ni}, \mathrm{Al}$, and $\mathrm{Si}$ in the Hadean and Archean Earth's protocrust and in the Earth's continental crust are reported. The Archean Earth's protocrust (3.8-2.5 Gyrs ago) had a less basaltic composition (Fe $\sim 8 \%, \mathrm{Ni} \sim 0.8 \%, \mathrm{Al} \sim 7 \%, \mathrm{Si} \sim 26 \%$ ) (Taylor \& McLennan 1996, 2005; Favero \& Jobstraibizer 1996; Rudnick \& Fountain 1995; Konhauser et al 2009; Saito 2009; Egami 1975; National Academy of Science 1975; Yaroshevsky 2006) compared to the previous period (Hadean Era, 4.5-3.8 Gyrs ago) (Taylor \& McLennan 2005; Hazen et al 2008), and a less Sialic composition compared to the concentrations in the Earth's continental crust today: $\mathrm{Fe} \sim 4 \%, \mathrm{Ni} \sim 0.01 \%, \mathrm{Al} \sim 8 \%, \mathrm{Si} \sim 28 \%$. (Taylor \& McLennan 1996, 2005; Favero \& Jobstraibizer 1996; Doglioni 2007; National Academy of Science 1975). Considering piezonuclear reactions $(1,2,4)$, the overall $12 \%$ decrease in the heavier elements ( $\mathrm{Fe}$ and $\mathrm{Ni}$ ) is consistently balanced by the $\mathrm{Al}$ and $\mathrm{Si}$ increase and assuming an increase in $\mathrm{Mg}$, according to reaction (2), equal to that of $\mathrm{Si}$ over the last 4.5 billion years.

and more recent times (figure 9). The Earth's protocrust in the Hadean era was strongly basaltic, with a composition similar to that of the proto-planets (chondrites) (Taylor \& McLennan 1996, 2005; Favero \& Jobstraibizer 1996). 
In particular, piezonuclear reactions $(1,2,4)$ seem to be the cause of the abrupt variations shown in figure 9. Piezonuclear reaction (2) implies that not only the Si mass percentage should increase overall by about $4 \%$ but also that of $\mathrm{Mg}$. However, the latter increase, due to piezonuclear reaction (2), cannot be revealed from geological data of sediments in the Earth's continental crust. As a matter of fact, $\mathrm{Mg}$ is not only a resulting element, as shown by piezonuclear reaction (2), but can also be considered as a starting element of another possible piezonuclear reaction (Carpinteri \& Manuello 2011):

$$
\mathrm{Mg}_{12}^{24} \rightarrow 2 \mathrm{C}_{6}^{12}
$$

Reaction (6) could be very important for the evolution of both the Earth's crust and the Earth's atmosphere, and considered as a valid explanation for the high level of $\mathrm{CO}_{2}$ concentration $(\sim 15 \%)$ in the Archean Earth's atmosphere (Liu 2004). In addition, the large amount of C produced by $\mathrm{Mg}$ transformation ( $\sim 3.5 \%$ of the Earth's crust) has undergone a slow but continuous diminishing in the $\mathrm{CO}_{2}$ composition of the Earth's atmosphere, as a result of the escape which also involves other atmospheric gases like He and H (Catling \& Zahnle 2009).

Piezonuclear reaction (6) can also be put into correlation with the increase in seismic activity that has occurred over the last century (Aki 1983). Very recent evidence has shown $\mathrm{CO}_{2}$ emissions in correspondence to seismic activity (Padron et al 2008): significant changes in the emission of carbon dioxide were recorded in a geochemical station at El Hierro, in the Canary Islands, before the occurrence of several seismic events during the year 2004. Appreciable precursory $\mathrm{CO}_{2}$ emissions were observed to start before seismic events of relevant magnitude, and to reach their maximum values some days before the earthquakes (Padron et al 2008).

\section{Conclusions}

By subjecting quasi-brittle materials such as granitic rocks to compression tests, it is observed that EM emission during the failure process, which is highly suggestive of charge redistribution, but also neutron bursts, necessarily involving nuclear reactions.

In this paper, we have analysed the mechanical behaviour of Luserna stone specimens loaded in compression up to their failure by EME signals, and we observed that the EME generally takes place only in correspondence to sharp stress drops in the load vs. time diagrams. These stress drops or 'snap-backs' are due to a rapid decay in the material's mechanical properties, generated by the formation of new micro-cracks during the loading process.

We have analysed, by means of $\mathrm{He}^{3}$ neutron detector, specimens of the same material (Luserna stone) characterized by different size and slenderness. The experimental results show that a volume approximately exceeding $200 \mathrm{~cm}^{3}$, combined with the extreme brittleness of the tested material, represents a critical threshold value for a neutron emission of about one order of magnitude higher than the ordinary background. In particular, in the case of specimen P6, with a volume of about $233 \mathrm{~cm}^{3}$, a very high amplitude EME $(16 \mu \mathrm{T})$ and a neutron emission of about five times the neutron background level were observed concomitant with the sharp stress drop at the time of failure. Moreover, as in the preliminary tests, the maximum neutron emissions exceeding by about one order of magnitude the ordinary background were obtained from test specimens with a volume larger than the threshold value of $360 \mathrm{~cm}^{3}$.

Our conjecture, also confirmed by the Energy Dispersive X-ray Spectroscopy (EDS) tests, is that piezonuclear reactions involving fission of iron into aluminum, or into magnesium and silicon, should have occurred during compression on the tested specimens. This hypothesis seems to find surprising evidence and confirmation at the Earth crust scale from both the geomechanical and the geochemical points of view. In this way, plate tectonics and the connected plate 
collision and subduction phenomena are useful to understand not only the morphology of our planet, but also its compositional evolution. Finally, through experimental and theoretical studies of electromagnetic emissions, neutron emissions and piezonuclear fission reactions from brittle fracture, it will also be possible to explore new and interesting application fields, such as short-term prediction and monitoring of earthquakes using both electromagnetic and neutron measurements.

The financial support provided by the Regione Piemonte RE-FRESCOS Project, is gratefully acknowledged. Special thanks are due to Prof. F Cardone from CNR in Roma for his previous extensive collaboration. The authors wish to acknowledge Dr. A Schiavi and Mr. A Agosto from the National Research Institute of Metrology - INRIM for their kind collaboration, and are also grateful to Dr. A Zanini, Dr. L Visca for their valuable assistance in the neutron detection and measurement.

\section{References}

Aki K 1983 Strong motion seismology, In Earthquakes: Observation, theory and interpretation, H Kanamori and E Boschi (eds) (Amsterdam: North-Holland Pub. Co.)

Anbar A D 2008 Elements and evolution. Science 322: 1481-1482

Arata Y and Zhang Y 1995 Achievement of solid-state plasma fusion ('cold-fusion'). Proc. Jpn. Acad. Ser. B 71: 304-309

Arata Y, Fujita H and Zhang Y 2002 Intense deuterium nuclear fusion of pycnodeuterium-lumps coagulated locally within highly deuterated atom clusters. Proc. Jpn. Acad. 78 Ser. B: 201-204

Basile-Doelsch I 2006 Si stable isotope in the Earth's surface: A review. J. Geochem. Explor. 88: 252-256

Basile-Doelsch I, Meunier J D and Parron C 2005 Another continental pool in the terrestrial silicon cycle. Nature 433: 399-402

Canfiled D E 1998 A new model for Proterozoic ocean chemistry. Nature 396: 450-453

Cardone F, Carpinteri A and Lacidogna G 2009 Piezonuclear neutrons from fracturing of inert solids. Phys. Lett. A 373: 4158-4163

Carpinteri A 1986 Mechanical damage and crack growth in concrete: Plastic collapse to brittle fracture (Dordrecht: Martinus Nijhoff Publishers)

Carpinteri A 1989 Cusp catastrophe interpretation of fracture instability. J. Mech. Phys. Solids 37: 567-582

Carpinteri A 1990 A catastrophe theory approach to fracture mechanics. Int. J. Fract. 44: 57-69

Carpinteri A 1994 Scaling laws and renormalization groups for strength and toughness of disordered materials. Int. J. Solids Struct. 31: 291-302

Carpinteri A, Lacidogna G and Pugno N 2006a Richter's laws at the laboratory scale interpreted by acoustic emission. Mag. Concr. Res. 58: 619-625

Carpinteri A, Lacidogna G and Niccolini G 2006b Critical behaviour in concrete structures and damage localization by acoustic emission. Key Eng. Mater. 312: 305-310

Carpinteri A, Lacidogna G and Pugno N 2007 Structural damage diagnosis and life-time assessment by acoustic emission monitoring. Eng. Fract. Mech. 74: 273-289

Carpinteri A, Cardone F and Lacidogna G 2009a Piezonuclear neutrons from brittle fracture: Early results of mechanical compression tests. Strain 45: 332-339. Presented at the Turin Academy of Sciences on December 10, 2008. Proc. of the Turin Academy of Sciences, Ser. V, 2010 33: 27-42

Carpinteri A, Cardone F and Lacidogna G 2009b Energy emissions from failure phenomena: mechanical, electromagnetic, nuclear. Exp. Mech. 50: 1235-2010

Carpinteri A, Lacidogna G and Niccolini G 2009c Fractal analysis of damage detected in concrete structural elements under loading. Chaos, Solitons and Fractals 42: 2047-2056

Carpinteri A, Lacidogna G and Puzzi S 2009d From criticality to final collapse: Evolution of the b-value from 1.5 to 1.0. Chaos, Solitons and Fractals 41: 843-853 
Carpinteri A, Lacidogna G, Niccolini G and Puzzi S 2009e Morphological fractal dimension versus powerlaw exponent in the scaling of damaged media. Int. J. Damage Mech. 18: 259-282

Carpinteri A, Chiodoni A, Manuello A and Sandrone R 2011a Compositional and microchemical evidence of piezonuclear fission reactions in rock specimens subjected to compression tests. Strain. 47 (Suppl. 2): 282-292

Carpinteri A, Lacidogna G, Manuello A, Niccolini G, Schiavi A and Agosto A 2011b Mechanical and electromagnetic emissions related to stress-induced cracks. Exp. Tech. (doi:10.1111/j.1747-1567. 2011.00709.x)

Carpinteri A and Manuello A 2011 Geomechanical and geochemical evidence of piezonuclear fission reactions in the Earth's crust. Strain. 47 (Suppl.2): 267-281

Catling C D and Zahnle K J 2009 The planetary air leak. Sci. Am. 300(5): 24-31

Condie K C 1976 Plate tectonics and crustal evolution. New York, Toronto, Oxford, Sydney, Braunshweig, Paris: Pergamon Press

De la Rocha C L, Brzezinski M and De Niro M J 2000 A first look at the distribution of the stable isotopes of silicon in natural waters. Geochim. Cosmochim. Acta 64(14): 2467-2477

Derjaguin B V et al 1989 Titanium fracture yields neutrons? Nature 34: 492

Diebner K 1962 Fusionsprozesse mit Hilfe konvergenter Stosswellen - einige aeltere und neuere Versuche und Ueberlegungen. Kerntechnik. 3: 89-93

Doglioni C 2007 Interno della Terra, Treccani, Enciclopedia Scienza e Tecnica, 595-605

Egami F 1975 Minor elements and evolution. J. Mol. Evol. 4(2): 113-120

Enomoto H and Hashimoto H 1994 in Electromagnetic phenomena related to earthquake prediction, M Hayakawa and Y Fujinawa (eds) (Tokyo: Terra Sci. Pub Co.) pp. 261-269

Favero G and Jobstraibizer P 1996 The distribution of aluminum in the Earth: From cosmogenesis to Sial evolution. Coord. Chem. Rev. 149: 467-400

Foing B 2005 Earth's childhood attic. Astrobiol. Mag. Retrospection (on-line) February 23

Fowler C M R 2005 The solid earth: An introduction to global geophysics (Cambridge: Cambridge University Press)

Fraser-Smith A C, Barnardi A, McGill P R, Ladd M E, Helliwell R A and Villard O G 1990 Low-Frequency Magnetic Field Measurements near the Epicenter of the Ms 7.1 Loma Prieta Earthquake. Geophys. Res. Lett. 17: 1465-1468

Frid V, Rabinovitch A and Bahat D 2003 Fracture induced electromagnetic radiation. J. Phys. D 36: 16201628

Fujii M F et al 2002 Neutron emission from fracture of piezoelectric materials in deuterium atmosphere. Jpn. J. Appl. Phys. Pt.1, 41: 2115-2119

Fukui K, Okubo S and Terashima T 2005 Electromagnetic radiation from rock during uniaxial compression testing: The effects of rock characteristics and test conditions. Rock Mech. Rock Eng. 38: 411-423

Galimov E M 2005 Redox evolution of the Earth caused by a multistage formation of its core. Earth Planet. Sci. Lett. 233: 263-276

Gokhberg M B, Morgunov V A, Yoshino T and Tomizawa I 1982 Experimental measurements of electromagnetic emissions possible related to earthquakes in Japan. J. Geophys. Res. 87: 7824-7828

Hazen M H et al 2008 Mineral evolution. Am. Mineral. 93: 1693-1720

Holland H D 2006 The oxygenation of the atmosphere and oceans. Philos. Trans. R. Soc. Lond., Ser. B 361: 903-915

Hudson J A, Crouch S L and Fairhurst C 1972 Soft, stiff and servo-controlled testing machines: A review with reference to rock failure. Eng. Geol. 6: 155-189

Kaliski S 1976 Critical masses of miniexplosion in fission-fusion hybrid systems. J. Tech. Phys. 17: 99-108

Kaliski S 1978 Bi-conical system of concentric explosive compression of D-T. J. Tech. Phys. 19: 283-289

Key Iron Deposits of the World. Available at http://www.portergeo.com.au/tours/iron2002/-iron2002 depm2b.asp; last accessed October 2009

Kholodov V N and Butuzova G Y 2008 Siderite formation and evolution on sedimentary iron ore deposition in the Earth's history. Geol. Ore Depos. 50(4): 299-319 
Konhauser K O et al 2009 Oceanic nickel depletion and a methanogen famine before the Great Oxidation Event. Nature 458: 750-754

Kuzhevskij B M, Yu Nechaev O, Sigaeva E A and Zakharov V A 2003a Neutron flux variations near the Earth's crust. A possible tectonic activity detection. Nat. Hazards Earth Syst. Sci. 3: 637-645

Kuzhevskij B M, Yu Nechaev O and Sigaeva E A 2003b Distribution of neutrons near the Earth's surface. Nat. Hazards Earth Syst. Sci. 3: 255-262

Lacidogna G, Manuello A, Carpinteri A, Niccolini G, Agosto A and Durin G 2010 Acoustic and electromagnetic emissions in rocks under compression. Proc. of SEM Annual Conf. \& Exp. on Exp. and Appl. Mech., Indianapolis, 7-10 June 2010, Paper No. 433

Lacidogna G, Carpinteri A, Manuello A, Durin G, Schiavi A, Niccolini G and Agosto A 2011 Acoustic and electromagnetic emissions as precursor phenomena in failure processes. Strain. 47 (Suppl. 2): 144-152

Liu L 2004 The inception of the oceans and $\mathrm{CO}_{2}$-atmosphere in the early history of the Earth. Earth Planet. Sci. Lett. 227: 179-184

Lockner D A, Byerlee J D, Kuksenko V, Ponomarev A and Sidorin A 1991 Quasi static fault growth and shear fracture energy in granite. Nature 350: 39-42

Lunine E J I 1998 Earth: Evolution of a habitable world (Cambridge, New York, Melbourne: Cambridge University Press)

Miroshnichenko M and Kuksenko V 1980 Study of electromagnetic pulses in initiation of cracks in solid dielectrics. Sov. Phys., Solid State 22: 895-896

Mogi K 1962 Study of elastic shocks caused by the fracture of heterogeneous materials and its relation to earthquake phenomena. Bull. Earthq. Res. Inst. 40: 125-173

Natl. Academy of Sciences 1975 Medical and Biological Effects of Environmental Pollutants: Nickel. Proc. Natl. Acad. Sci. Washington, DC

Niccolini G, Bosia F, Carpinteri A, Lacidogna G, Manuello A and Pugno N 2009 Self-similarity of waiting times in fracture systems. Phys. Rev. E 80: 026101

Niccolini G, Schiavi A, Tarizzo P, Carpinteri A, Lacidogna G and A Manuello 2010 Scaling in temporal occurrence of quasi-rigid-body vibration pulses due to macrofractures. Phys. Rev. E 82: 046115

Niccolini G, Carpinteri A, Lacidogna G and Manuello A 2011 Acoustic emission monitoring of the Syracuse Athena Temple: Scale invariance in the timing of ruptures. Phys. Rev. Lett. 106: 108503

Nitsan U 1977 Electromagnetic emission accompanying fracture of quartz-bearing rocks. Geophys. Res. Lett. 4: 333-337

Ogawa T, Oike K and Miura T 1985 Electromagnetic radiations from rocks. J. Geophys. Res. 90: 62456249

Ohtsu M 1996 The history and development of acoustic emission in concrete engineering. Mag. Concr. Res. 48: $321-330$

O'Keefe S G and Thiel D V 1995 A mechanism for the production of electromagnetic radiation during fracture of brittle materials. Phys. Earth Planet. Inter. 89: 127-135

Padron E, Melian G, Marrero R, Nolasco D, Barrancos J, Padilla G, Hernandez P A and Perez N M 2008 Changes in the diffuse $\mathrm{CO}_{2}$ emission and relation to seismic activity in and around El Hierro, Canary Islands. Pure Appl. Geophys. 165: 95-114

Parrot M 1994 in Electromagnetic phenomena related to earthquake prediction, M Hayakawa and Y Fujinawa (eds) (Tokyo: Terra Sci. Pub Co.) 61-372

Preparata G 1991 A new look at solid-state fractures, particle emissions and 'cold' nuclear fusion. Il Nuovo Cimento. 104 A: 1259-1263

Rabinovitch A, Frid V and Bahat D 2007 Surface oscillations. A possible source of fracture induced electromagnetic oscillations. Tectonophysics 431: 15-21

Ragueneau O et al 2000 A review of the Si cycle in the modern ocean: Recent progress and missing gaps in the application of biogenic opal as a paleoproductivity proxy. Glob. Planet. Change 26: 317-365

Roy I, Sarkar B C and Chattopadhyay A 2001 MINFO-a prototype mineral information database for iron ore resourcers of India. Comp. Geosci. 27: 357-361

Rudnick R L and Fountain D M 1995 Nature and composition of the continental crust: A lower crustal perspective. Rev. Geophys. 33(3): 267-309 
Saito M A 2009 Less nickel for more oxygen. Nature 458: 714-715

Scott D F, Williams T J and Knoll S J 2004 Investigation of electromagnetic emissions in a deep underground mine. Proc. of the 23rd Int. Conference on Ground Control in Mining, Morgantown, 3-5 August 2004, 125-132

Shcherbakov R and Turcotte D L 2003 Damage and self-similarity in fracture. Theor. Appl. Fract. Mech. 39: $245-258$

Sigman D, Jaccard S and Hau F 2004 Polar ocean stratification in a cold climate. Nature 428: 59-63

Taleyarkhan R P, West C D, Cho J S, Lahey R T, Nigmatulin R I and Block R C 2002 Evidence for nuclear emissions during acoustic cavitation. Science 295: 1868-1873

Taylor S R and McLennan S M 1995 The geochemical evolution of the continental crust. Rev. Geophys. 33(2): 241-265

Taylor S R and McLennan S M 2009 Planetary crusts: Their composition, origin and evolution (Cambridge: Cambridge University Press)

Volodichev N N, Kuzhevskij B M, Yu Nechaev O, Panasyuk M I, Podorolsky A and Shavrin P I 2000 Sun-Moon-Earth connections: The neutron intensity splashes and seismic activity. Astron. Vestn. 34(2): $188-190$

Warwick J W, Stoker C and Meyer T R 1982 Radio emission associated with rock fracture: Possible application to the great Chilean earthquake of May 22, 1960. J. Geophys. Res. 87: 2851-2859

Winterberg F 1984 Autocatalytic fusion-fission implosions. Atom.-Kerntechnik. 44: 146

World Iron Ore producers. Available at http://www.mapsofworld.com/minerals/world-iron-ore-producers. html; last accessed October 2009

World Mineral Resources Map. Available at http://www.mapsofworld.com/world-mineral-map.htm, last accessed October 2009

Yamada I, Masuda K and Mizutni H 1989 Electromagnetic and acoustic emission associated with rock fracture. Phys. Earth Planet. Inter. 57: 157-168

Yamaguchi K E 2005 Evolution of the geochemical cycle of Fe trough geological time: Iron isotope perspective. Front. Res. Earth Evol. 2: 4-24

Yaroshevsky A A 2006 Abundances of chemical elements in the Earth's crust. Geochem. Int. 44(1): 54-62 